\title{
Management and Operation Strategy of Stadiums in the Context of the Internet Plus Sports
}

\author{
Donghua Zhou \\ Wuhan Business University \\ Wuhan, China 430056
}

\author{
Xing Yan \\ Wuhan Business University \\ Wuhan, China 430056
}

\begin{abstract}
Under the background of the development of the Internet plus sports, this paper uses the method of literature review, field survey, theory combining with practice to analyze the current development situation of our country sports venues, to research management and operation strategy of stadiums, to discuss about innovation pattern of stadium operations, such as using business to support the stadium, in return, using the stadium to improve business, to satisfy the needs of the diversified society, for the purpose of improving the economic benefits of gymnasiums and stadiums, and to provide a reference for construction and operation of sports venues in the context of the macro economy and management.
\end{abstract}

Keywords-the internet plus sport; sports stadiums; management and operation strategy

\section{INTRODUCTION}

In this information age, the Internet and mobile network terminals have been gradually entered and penetrated into all aspects of people's lives now. Many industries have timely used of the Internet + to create a new ecological and a new vitality. Traditional sports industry has also begun to use the Internet information technology to launch a new situation, Therefore, the intelligent facilities with "Internet +sports venues" is the inevitable trend of the development of sports venues in the new era .It is imperative to explore the operation and management of the stadium by a new business model.

\section{THE ECONOMIC BACKGROUND OF INTERNET + SPORTS}

"Internet +"refers to the rational use of the Internet platform, information and communication technology to combine the Internet and other industries, including the traditional industries, so as to create a new ecological environment in the new field. It is not a simple tool, but to change the industry to develop the energy of the new energy the same as the power to the industrial revolution. Internet + sports mean the Internet + traditional sports industry. By using the new method of the information and communication technology and Internet platform, to make a depth of integration in the traditional sports industry and Internet technology, to become a new element of traditional sports industry, to create a new development pattern of the sports industry.

With the development of the national economy, people pay much more attention to the needs of the spiritual and cultural fields, sports fitness and entertainment has gradually become a hot spot of consumption. The NO.46 document issued by the State Council in 2014 shows that we should promote the better and faster development of sports industry, and take the national fitness rose to the national strategic level. It also points out that in 2025 the sports industry will achieve an important indicator of the size of 5 trillion. Internet +was first put forward in the prime minister's government work report in 2015, National pay more attention to innovation and entrepreneurship with Internet. These policies relevant with sports industry have introduced by national and local government, in order to create a favorable external environment and policy support for "Internet + sports".

Sports venue plays an important role in the development of sports industry, which also plays an important part in meeting people's leisure and fitness needs. With the rapid development of Internet information technology, smart phone applications, online shopping, online payment and the Internet user community has gradually infiltrated and affected people's daily life, and in our country, the sports consumption population and the age of the network population has a high degree of coincidence. Therefore, the depth of the integration of the sports industry with Internet is a very potential market. Internet + sports, the new model, is not only to expand sports consumption and demand, but also to promote the development of the entire sports society and economy. Sports venues services can also use this new power from the Internet to make up for the imperfection of current stadium's low utilization rate and that the market in the allocation of capacity cannot effectively, and Internet + sports can get more effective development and utilization of the stadiums resources, can give full social service functions of stadiums to improve the stadiums' economic benefit.

\section{ANALYSIS ON THE PRESENT SituATION AND PROSPECT} OF SPORTS STADIUMS IN CHINA

\section{A. The Present Situation of the Operation and Management of Sports Stadiums in China}

In recent years, many kinds of large-scale sports events have been held, which speeded up the growth rate of the number of sports venues in China. According to statistic of the sixth general survey of sports ground by General Administration of sport of China, as of the end of 2013, there are a total of 169.46 ten thousand sports venues, the area is 
about 19.92 hundreds of millions squares meters. Compared with the last census, the number of national sports venues increased by 84.45 ten thousand, which nearly doubled. It is showed that the growth of construction of sports facilities is very fast, the number and size of the stadium is increased sharply, but there are many defects and problems in the management of sports venues. They are as follows:

1) Low stadium utilization rate, bad management of a large number of stadiums: According to incomplete statistics, the total number of stadiums in our country has reached about one million, but it is difficult to open to the public all day, the effective utilization ratio of stadium is even short of $30 \%$. Large sports venues are designed and built for hosting the high level events, the venue configuration is high and excessive, functional is relatively single, high operating costs, all these leading to the daily small events of the host cannot be afforded, the national fitness cannot use it .So it appears idle after the game, operational difficulties and other issues. The school sports venue which hold $2 / 3$ of the total number of stadiums are mainly used in physical education and teachers and students of physical exercise, truly open to the outside world is only $1 / 6$.

In the profitability of the stadium, golf course have the lowest utilization rate, only $12.5 \%$.The table tennis venue ' $\mathrm{s}$ average utilization rate is about $50 \%$, utilization rate highest comprehensive class stadium is only $56.8 \%$. A large number of sports equipment is often in a state of lying aside, it is more obvious during the workday. So the operating conditions of the stadium are worse.

The serious shortage of stadiums and the long-term idle exist at the same time, sports venues resources cannot be reasonably planned and efficiently used. Therefore, the establishment of sports venues resources information service platform is particularly urgent.

2) Single stadium operation mode and restricted by operation system: At present, in our country, the contents of the stadium operation mainly focus on: Integrated domestic and international sporting events and art show; reception professional sports team training and commercial exhibition or venue rental business activities, in order to obtain the corresponding ticket sales, advertising revenue and venue rental, etc., , in a word, the operation mode is single.

Besides single management pattern, $67.9 \%$ of the stadiums attached to the state owned assets, which adopts the traditional government management pattern, that is, public welfare management mode. They mainly rely on national financial funds to maintain. This kind of operation system is not in line with the market, is not conducive to sound and perfect the market operation of the stadium. Therefore, only innovating the stadium management mode, establishing a scientific and reasonable operating mechanism can the stadium service industry be promoted rapid development?

3) Lack of better marketing approach, lack of professional and technical personnel: Nowadays, the marketing tools which sports stadiums in the fitness and entertainment industry use , is the general and traditional way that occupy the leading position. While, some marketing tools and channels with the characteristics of the era of marketing have not yet been popularized and promoted. Most sports venues are also relatively passive to use operating marketing tools, which lead the stadium management and operation to having no new vitality and without enough attractive power.

In our country, the resources of talents in the sports management are scarce. At present, the sports industry management practitioners who understand sports management and sports are very few. Most sports venue management personnel are from the general sports cadres, retired athletes, whose professional quality is not high, which objectively limits the development of stadium management.

Therefore, creating a marketing mode with the characteristics of the times and training professional sports management personnel are also the most important things to promote the development of sports venues.

\section{B. Analysis of the Prospects of the Internet+ Sports Venues}

1) Consumer demand for sports stadiums: With the improvement of people's spiritual and cultural level as well as the enhancement of fitness consciousness, "buying health" has become a new form of people's consumption. A large number of recreational fitness clubs and professional sports venues have been built, people's requirements for the fitness environment is also getting higher and higher. Fitness venues are from the original simple outdoor transferring to indoor with fully functional facilities services.

2) Inadequate supply of effective resources of sports venues. Although the construction of sports venues in China is in a stage of rapid development, the number of related sports stadiums is also more and more, but the number of venues which can be fully open for the national fitness is very less.

The public demand for sports venues is expanding, and the shortage of effective venues resources supply, resulting in the contradiction between supply and demand. one hand ,the sports participants will be affected by the lack of space, open time constraints and leading to "movement difficulties" phenomenon, on the other hand, many stadium most of the time are in idle, site has not been very good use of and online pre-booked of electronic commerce system development is not perfect and leading to "operational difficulties" phenomenon. If we can use the Internet information technology, reasonable and effective and fully configured sports venues resources, using of the new $\mathrm{O} 2 \mathrm{O}$ model, and improve the online booking system, the sports venues resources will be used of more efficiently.

\section{THE DEVELOPMENT STRATEGY OF THE INTERNET+ STADIUM}

\section{A. Finding Sports Venues-Building the Information Public Service Platform of the Sports Facilities, Improving the Utilization Rate of the Venues}

By using of Internet information technology in the application of big data, we can construct the sports venues information public service platform. Moreover, we can improve the dedicated APP, first, we can classify the stadiums 
into different types according the region, and then, we can put all the information into the APP according to their different geographical relations, functional types of stadiums, location, open time, price, and the site of the spare, facilities and equipment and so on. At the same time, we also provide online booking site features to facilitate people to set aside venues in advance, and arrange additional dating features, the instructor who can make an appointment for the user according to the same sports preferences to choose fitness companions. So that people will be able to check the relevant information in the area of sports venues, according to the personal interests and their own needs to choose the right sports venues for exercise.

In addition, the users' personal information which they fill in registration will help to provide a reference for the relevant departments and managers according the age of the user, the nature of the work, economic and related statistics, and according to the needs of users to develop personalized services, and then achieve the purpose of precision oriented marketing, to achieve information aggregation, pricing and scheduled for a set of reasonable and orderly industrial chain, to optimize the utilization of sports venues.

\section{B. Intellectual Stadium-Innovating Operation Management Mode to Achieve the Wisdom Management of Sports Venues}

Exploring the role of the market mechanism can make stadium operation be truly integrated into the social market economy in this big environment. Immediately follow capital trends of the Internet sports industry venture, to develop a new financing platform and promote the pace of the stadium of the enterprise by making use of a variety of different models of business.

By using of high-tech information technology, we can provide a variety of personalized services, rich contents of the stadium business. We also should strengthen dedicated highspeed network infrastructure construction, integrate information application system and hardware equipment management system, and adopt intelligent management of the different levels according to the actual situation, to develop a variety of smart linkage service, to form ecological operation of the formation of both inside and outside the venue.
Wisdom stadium is not only using Internet technology to support the operation and management in the traditional security, management, service, but also refers to using hightech to improve the sports venues operation rate and utilization rate, to enhance the user experience, to provide a richer quality of service for physical exercise participants, for the purpose of realizing the intelligent, digitized and networked of stadium.

\section{Marketing Stadium-Comprehensive Application of Self Media Innovation Marketing Mode, Training Professional Talents}

Self media is widely used nowadays; everyone is the spreader of information. Stadium manager should have courage to innovate and explore the integration of Internet technology and sports venues, making full use of self media innovation and sports venues marketing model. Making use of We Chat mall develops "Blue Ocean", opening public service account timely to the user such as facility resources information to create a variety of preferential excitation method, in order to build a more perfect e-commerce platform, truly bring convenience to the public. We can use Weibo, blog and other sports user community to take efforts to build the stadium's official website, to launch a real-time interactive and popular topic to enhance the effect of communication, to strengthen the user's degree of adhesion. Integrate marketing to enhance the influence of the network marketing platform, the value of the Internet to maximize the spread of the Internet. Study the objective law of the development of sports market, to create more products and services to meet the needs of consumers, to accelerate the optimization and upgrading of the service of sports venues.

Using the Internet platform, open stadium management knowledge of online class, to let more sports industry practitioners and enthusiasts use spare time to learn professional knowledge and skills, to enhance the professional quality, to train professional and practical talents for the development of the sports industry. The stadiums' management strategy is shown in "Fig. 1".

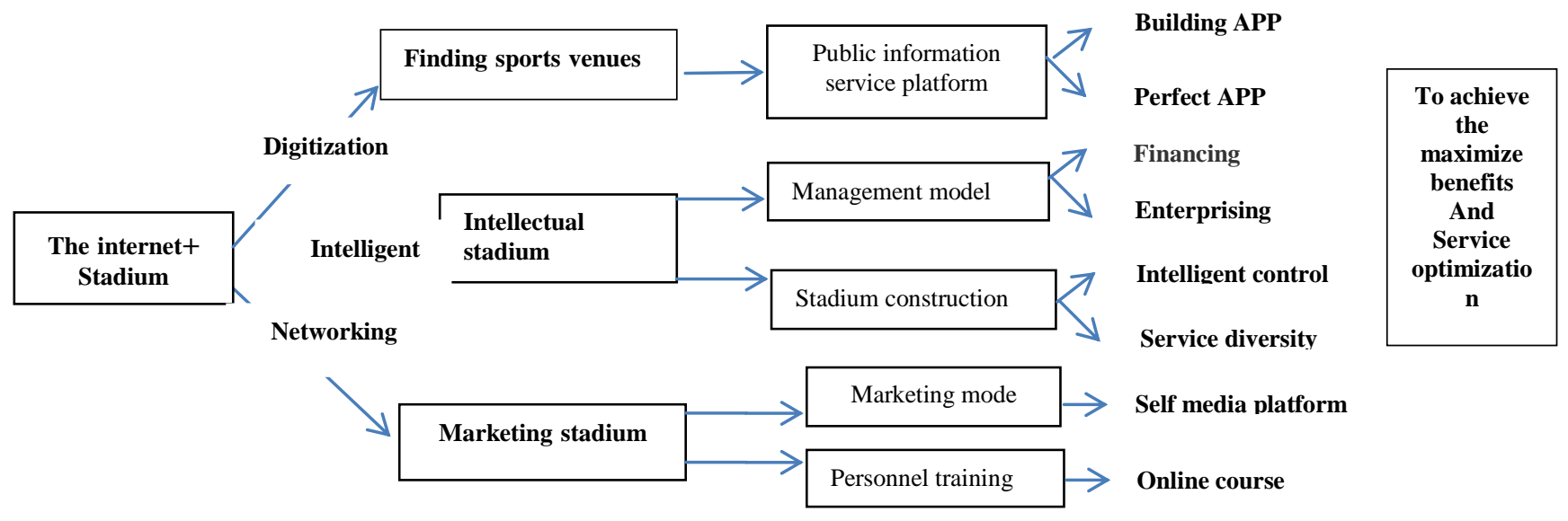

Fig. 1. The operation and management pattern of Internet + sports venues 


\section{CONCLUSION}

Sports venues are the important carrier for the public to exercise, to enrich the amateur spirit of cultural life and are an important carrier to show the level of competitive sports in China. Its operation mode has a great link with the realization of the development goal of the national fitness and improving the level of economic development of sports industry. At the same time, the development of the service industry of the sports facilities is also an important support for other industries. Therefore, sports venues and service industry in "Internet" "wings" embarked on a new development path, the development direction will be gradually clear, industry structure will be by the institution mainly gives priority to change of enterprises, institutions, management gradually realize systematic, professional and market-oriented operation to achieve maximum stadiums interests of optimization and serving for the masses. Venues will be intelligent due to the Internet and, internet management will be orderly. due to the Internet operation.

\section{REFERENCES}

[1] Jiang Yayu, Liu Shiwen. Methods and Approaches for Improvement of Students' Expressive Ability of Chinese Culture (2005. 3)

[2] Liao Huaying, Chen Feng. Research on the Expression Ability of Chinese Culture in English by Non-English Major Students (2011. 3)

[3] Hu Xiaorong. Research on the Expression Ability of Chinese Culture in English by English Major College Students (2015. 8)

[4] Luo Suqin, Li Xuan. Discussion on "Chinese Culture Aphasia" in English Teaching (2009. 6)

[5] Kong Weichen, Pattern seeking change of the internet +sports [J], China economic information, 2015(12):70-71

[6] This print editorial office, the water cube in Internet + Era [J], Tourism, 2016(2):144-149

[7] $\mathrm{Xu}$ Jiemo, Look at the Olympic Games, to explore the operation of the stadium [J], new economy, 2014(7):24-25

[8] QU Minghao. Research on Operating, Managing and Developing Strategies of Stadiums in Small and Medium - sized Cities Under the Background of Internet + [D]Journal of Baicheng Normal University,2015(12)104-107

[9] Yi Jiandong Three Major Problems Sports Venues Operation encounters [J], GLOBAL SPOTR MARKET, and 2010(2):14-15

[10] Zeng Jiehui. Internet + movement, the layout of sports venues intelligent [J], China security, 2015(18:21-24

[11] Wang Chunbo,Jin Haibo, Research on the present situation and Countermeasures of the operation mode of sports stadiums in China [J],MODERN ENTERPRISE EDUCATION,2015(1):74-75

[12] [8]Chen Yanxin, Wang Jian. The problems existing in the development of China's public sports stadiums, the future trend, the overseas experience and development[J],SPORTS SCIENCE,2013(10) : 3-13

[13] [9]Zhong Bingshu. National Fitness Program and Sports Leisure Industry [J].SPORTS SCIENCE, 2015(11):19-23 